\title{
The Foker Technique (FT) and Kimura Advancement (KA) for the Treatment of Children with Long-Gap Esophageal Atresia (LGEA): Lessons Learned at Two European Centers
}

\author{
Piotr Landowski ${ }^{3}$ Piotr Czauderna ${ }^{1}$ John Foker ${ }^{4}$ Holger Till2,5 \\ ${ }^{1}$ Department of Surgery and Urology for Children and Adolescents, \\ Medical University of Gdansk, Gdansk, Poland \\ 2 Department of Paediatric Surgery, University of Leipzig, Leipzig, \\ Germany \\ ${ }^{3}$ Department of Paediatrics, Gastroenterology, Hepatology, Medical \\ University of Gdansk, Gdansk, Poland \\ ${ }^{4}$ Department of Surgery, University of Minnesota Medical School, \\ Minneapolis, Minnesota, United States \\ ${ }^{5}$ Department of Paediatric and Adolescent Surgery, University of Graz, \\ Graz, Austria
}

Mariusz Sroka ${ }^{1}$ Robin Wachowiak ${ }^{2}$ Marcin Losin ${ }^{1} \quad$ Agnieszka Szlagatys-Sidorkiewicz $^{3}$

Address for correspondence and reprint requests Holger Till, MD, PhD, Department of Paediatric and Adolescent Surgery, University of Graz, Auenbruggerplatz 34, Graz 8036, Austria (e-mail: holger.till@medunigraz.at).

Eur J Pediatr Surg 2013;23:3-7.

\begin{abstract}
Keywords

- long gap

- esophageal atresia

- Foker

- Kimura

- multicenter

Introduction We present the experiences from two European centers performing the Foker technique (FT) of esophageal lengthening by axial traction and the Kimura advancement (KA) method of lengthening the upper pouch by extrathoracic resiting a spit fistula (SF) in children with long-gap esophageal atresia (LGEA, gap length $>5 \mathrm{~cm}$ ). Materials and Methods A total of 15 children were treated ( 8 pure EA, 6 lower tracheoesophageal fistula [TEF], and 1 upper TEF). Gaps ranged from 5 to $14 \mathrm{~cm}$. Nine children already had a SF. Patients were grouped according to the presence of a SF and the subsequent surgical strategy: Group A (no SF, $n=6$ ) received FT on both pouches. Group B (with SF, $n=6$ ) received KA of SF and FT of the lower pouch. Group C (with SF, $n=3$ ) received closure of the SF and subsequent Foker traction (CSFT) on both pouches.

Results Group A: Primary repairs for all six children (mean age 3 months, gap length $6.5 \mathrm{~cm}$ ) after a mean traction time of 3 weeks and a mean of 2.1 thoracotomies (range 2 to 3). Dilations were required in three out of six for anastomotic strictures with one perforation during the second dilation. Group B: All six children (mean age 16.4 months, gap length $9.5 \mathrm{~cm}$ ) had a primary anastomosis, although for two it was significantly delayed (48 and 143 weeks traction time) because of infections. The number of thoracotomies ranged from 2 to 8 (mean 3.6). Leaks occurred in five out of six anastomoses (responsive to conservative management). Two children developed severe strictures, which required the anastomosis to be redone. In group C (mean age 10.6 months, gap length $6.5 \mathrm{~cm}$ ), several major complications occurred. The three SF closures leaked (one iatrogenic) causing severe mediastinitis. CSFT was successful in
\end{abstract}

received

January 6, 2013

accepted

January 7, 2013

published online

February 1, 2013 (c) 2013 Georg Thieme Verlag KG

Stuttgart · New York
DOI http://dx.doi.org/ 10.1055/s-0033-1333891. ISSN 0939-7248. 
only one case and the other two children had an esophageal replacement (stomach, jejunum). No deaths occurred in the series.

Conclusion FT of both pouches (group A) resulted in primary repairs of all six LGEA patients. The combination of KA and FT (group B) resulted in an equivalent rate of primary repairs, but with an increased number of thoracotomies and rate of complications compared with group A. CSFT (group C) resulted in a high failure rate. More data are needed (we propose a multicenter registry) to elucidate the safety and efficacy of each elongation technique and to establish an algorithm with clearer inclusion and exclusion criteria.

\section{Introduction}

For children at our two institutions with long-gap esophageal atresia (LGEA), defined as a gap length of at least $5 \mathrm{~cm}$, several techniques of esophageal lengthening were used to achieve a primary anastomosis. Treatment of LGEA has proven difficult and several approaches have been used including bouginage of both pouches with dilators and time alone to achieve a delayed primary repair but, only a few studies have provided data on efficacy and safety. ${ }^{1,2}$ For those children in whom a spit fistula (SF) has already been created, the Kimura advancement (KA) technique is an alternative and consists of a multistaged extrathoracic elongation of the proximal esophagus by moving the cutaneous stoma progressively further down the anterior chest wall. ${ }^{3}$ More recently, Foker et $\mathrm{al}^{4,5}$ described a technique (Foker technique [FT]) using traction sutures on the esophageal segment(s) to induce growth until a primary repair was possible. To gain data about these techniques and their combination, we pooled the experiences of two European centers treating children with LGEA.

\section{Materials and Methods}

From 2007 to 2010, 15 children with LGEA were treated: 8 with pure EA, 6 with a lower tracheoesophageal fistula (TEF), and 1 with an upper TEF. Nine children already had a SF created elsewhere. At presentation, the gap ranged from 5 to $14 \mathrm{~cm}$ ( - Table 1). Patients were grouped according to whether or not a SF was present and by the subsequent surgical strategies: Group A (no SF, $n=6$ ) received FT on both pouches. Group B (with SF, $n=6$ ) received KA of SF and FT of the lower pouch. Group C (with SF, $n=3$ ) received closure of the SF and subsequent Foker technique (CSFT) on both pouches.

\section{Results}

In group A (mean age 3 months, mean gap length $6.5 \mathrm{~cm}$ ), a primary anastomosis was achieved for all six children after a mean traction time of 3 weeks and 2 to 3 thoracotomies. In detail ( - Table 1), five patients required only one thoracotomy for placement of traction sutures and a second for the esophageal repair. In one case (a 2-month-old boy with EAtype Vogt 3a and a gap length of $7 \mathrm{~cm}$ ), two thoracotomies were required: First, the upper TEF was closed and the pouch was fixed internally to the vertebral column under slight tension to allow healing. After 4 weeks, the internal traction was converted into an external FT followed by primary anastomosis. In group A, there was only one late complication; during the second dilation ( 5 weeks after the repair), the anastomosis was severely disrupted, which required immediate excision of the stricture and reanastomosis. This healed well without further complications. In group B, all six children (mean age 16.4 months, mean gap length $9.5 \mathrm{~cm}$ ) had a primary anastomosis, although it was delayed in $2(48,143$ weeks) because of infection. The elongation procedures required a mean of 3.6 thoracotomies (range 2 to 8 ). In three patients, a SF infection occurred after KA and in one child, an empyema from a lower pouch perforation during FT. Anastomotic leakage occurred in five out of six cases and all healed spontaneously. Repeated dilations were required in all and in two out of six cases, the anastomosis was redone because of an intractable stricture. Finally, in one patient from group B, the distal esophagus became necrotic after repair of a hiatal hernia and fundoplication which required a later jejunal interposition.

In group $\mathrm{C}$ (mean age 10.6 months, mean gap length $6.5 \mathrm{~cm}$ ) only one out of three patients had a final anastomosis. In this group, major complications occurred during the elongation procedures and the FT had to be aborted in two out of three. All three patients had severe infectious complications following the closure of the SF from two leaks and one iatrogenic perforation. Two cases (age 11 and 13 months with gaps of 7 and $5.5 \mathrm{~cm}$ ) failed to achieve adequate length despite several attempts at reconfiguring the traction sutures. One of these patients was converted from FT to KA of the upper pouch without significant improvement. These two patients had a later esophageal replacement (stomach, jejunum). Only one child age 8 months, with a gap of $7 \mathrm{~cm}$ ) had an esophageal anastomosis 18 weeks later. A significant anastomotic leak occurred, however, which required five thoracotomies for drainage and ultimately a revision of the anastomosis.

\section{Discussion}

In children with LGEA, opinions differ significantly about the "best" solution for the child. ${ }^{1}$ Although there is general agreement that "one's own esophagus is best," a strong 
Foker Technique and Kimura Advancement for the Treatment of Children with LGEA Sroka et al. 5

\begin{tabular}{|c|c|c|c|c|c|c|c|c|c|c|c|c|c|c|c|c|c|c|c|}
\hline \multicolumn{2}{|c|}{$\simeq$} & 号 & 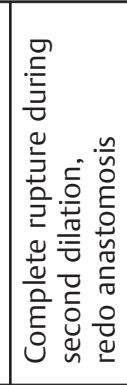 & \begin{tabular}{|c} 
\\
\\
$\stackrel{0}{0}$ \\
$\frac{0}{2}$
\end{tabular} & 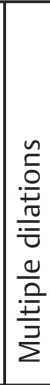 & 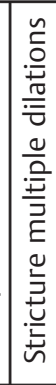 & & 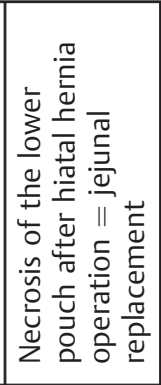 & 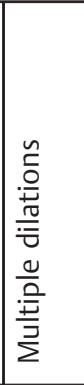 & 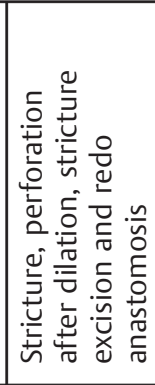 & 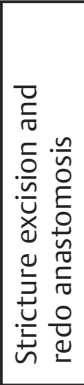 & 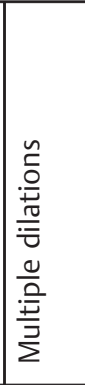 & 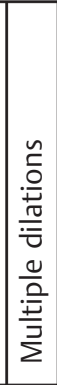 & & 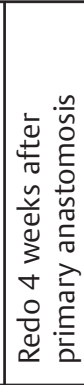 & & & & 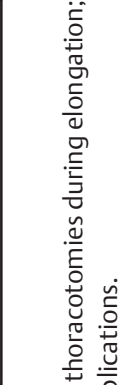 \\
\hline$=$ & $\mid \begin{array}{l}0 \\
\tilde{0} \\
z \\
z\end{array}$ & $\mid \begin{array}{l}0 \\
\tilde{\sigma} \\
z\end{array}$ & 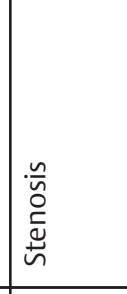 & $\begin{array}{l}0 \\
\tilde{\Xi} \\
\tilde{z}\end{array}$ & 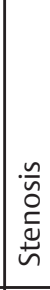 & 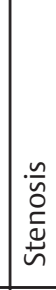 & & 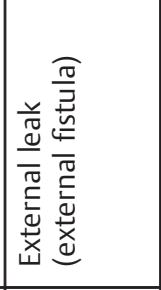 & 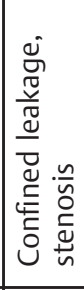 & 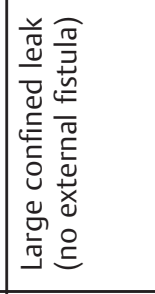 & 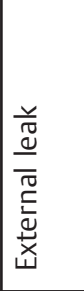 & 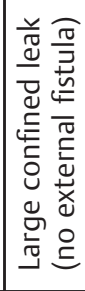 & 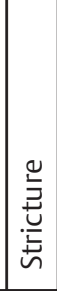 & & 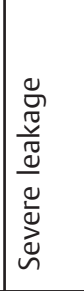 & & & & 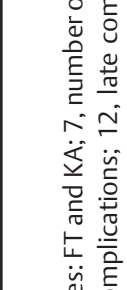 \\
\hline 으 & $\sim$ & $\sim$ & 6 & $m$ & - & $\nabla$ & $m$ & 으 & $\stackrel{\sim}{\simeq}$ & $\stackrel{m}{\leftarrow}$ & $\sim$ & $\stackrel{\infty}{+}$ & $m$ & $\stackrel{\varphi}{m}$ & $\stackrel{\infty}{\longrightarrow}$ & & & & \\
\hline$a$ & $\stackrel{\check{\Perp}}{\rightleftharpoons}$ & $\stackrel{\tilde{y}}{\varnothing}$ & $\stackrel{\check{\nu}}{\nu}$ & $\stackrel{\tilde{u}}{\succ}$ & $\stackrel{\check{\nu}}{\varnothing}$ & $\stackrel{\check{\nu}}{\rightleftharpoons}$ & & $\stackrel{\check{\nu}}{\nu}$ & $\stackrel{\check{\nu}}{\nu}$ & $\stackrel{\Perp}{\nu}$ & $\stackrel{\ddot{y}}{\nu}$ & $\stackrel{\check{\nu}}{\nu}$ & $\stackrel{\check{\nu}}{\check{\nu}}$ & & $\stackrel{\check{\Perp}}{\nu}$ & 운 & 2 & & \\
\hline$\infty$ & $\begin{array}{l}0 \\
\tilde{0} \\
\tilde{z} \\
\end{array}$ & $\mid \begin{array}{l}0 \\
\tilde{\sigma} \\
z\end{array}$ & $\begin{array}{l}0 \\
\text { こे } \\
z\end{array}$ & $\mid \begin{array}{l}0 \\
\tilde{0} \\
\text { z }\end{array}$ & 号 & 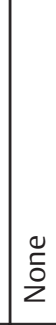 & & 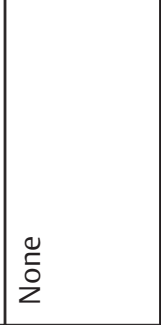 & $\begin{array}{l}\text { In } \\
\text { Oे }\end{array}$ & 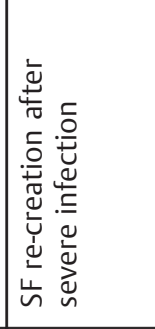 & 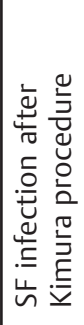 & 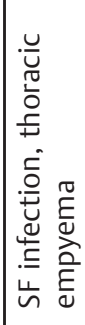 & \begin{tabular}{|l} 
\\
. \\
$\check{0}$ \\
2
\end{tabular} & & 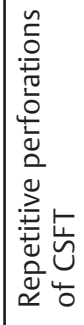 & 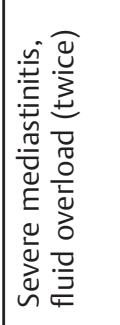 & 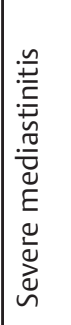 & & 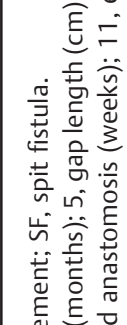 \\
\hline N & $\sim$ & $\sim$ & $m$ & $\sim$ & $\sim$ & $\sim$ & & $m$ & $\nabla$ & $\infty$ & $\sim$ & $m$ & $\sim$ & & $\nabla$ & 6 & in & & 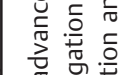 \\
\hline 6 & 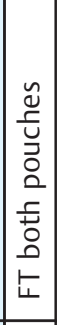 & 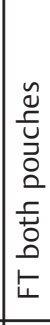 & 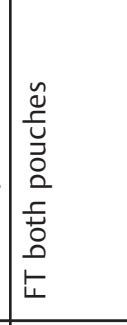 & 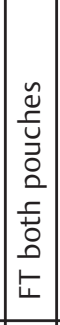 & 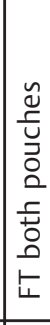 & 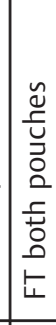 & & 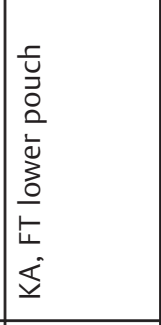 & 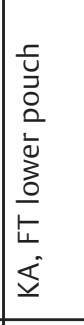 & 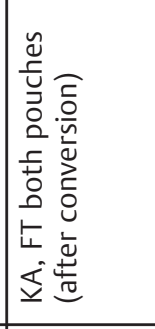 & 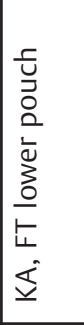 & 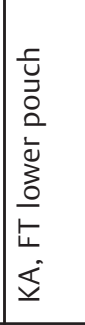 & 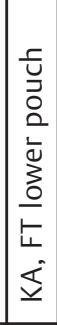 & & 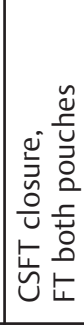 & 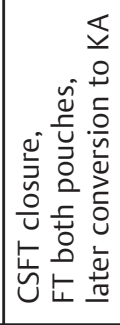 & 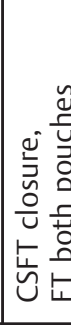 & & 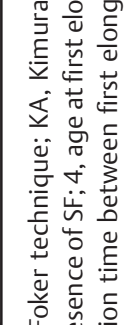 \\
\hline เn & 6 & & & & & & $\stackrel{n}{n}$ & & & & & & & & & & & & \\
\hline$\nabla$ & $\sim$ & $\sim$ & $\sim$ & in & $\sim$ & in & $m$ & 으 & $\stackrel{2}{\square}$ & $\infty$ & $\underset{N}{\sim}$ & 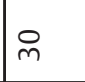 & 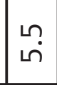 & $\begin{array}{l}\stackrel{\bullet}{0} \\
\stackrel{0}{0}\end{array}$ & $\infty$ & $\mp$ & $\stackrel{m}{r}$ & $\stackrel{\circ}{-}$ & \\
\hline$m$ & $\begin{array}{l}\dot{\omega} \\
\stackrel{0}{z} \\
z\end{array}$ & $\begin{array}{l}\Delta \\
\tilde{n} \\
0 \\
z\end{array}$ & $\begin{array}{l}\Delta \\
\dot{n} \\
0 \\
z\end{array}$ & $\begin{array}{l}\Delta \\
\tilde{n} \\
2 \\
z\end{array}$ & $\begin{array}{l}\Delta \\
\text { un } \\
2 \\
z\end{array}$ & 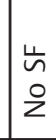 & & 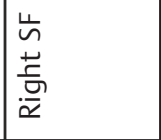 & $\begin{array}{l}\Delta \\
\tilde{\omega} \\
\stackrel{\omega}{\omega}\end{array}$ & $\begin{array}{l}\text { 岕 } \\
\text { 売 } \\
\frac{\vec{\alpha}}{\alpha}\end{array}$ & 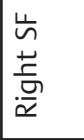 & $\begin{array}{l}\Delta \\
\tilde{\omega} \\
\stackrel{\omega}{\omega}\end{array}$ & 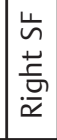 & & 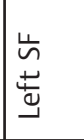 & $\begin{array}{l}\Delta \\
\tilde{\omega} \\
\stackrel{\omega}{\omega}\end{array}$ & $\begin{array}{l}\text { 岕 } \\
\text { 喜 } \\
\frac{\bar{\alpha}}{\alpha}\end{array}$ & & 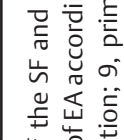 \\
\hline$N$ & $\sim$ & $\sim$ & 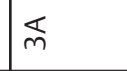 & $\sim$ & $\stackrel{m}{m}$ & $\stackrel{m}{m}$ & & $\stackrel{m}{m}$ & $\stackrel{m}{m}$ & $\sim$ & $\sim$ & $\stackrel{m}{m}$ & $\sim$ & & $\sim$ & $\sim$ & $\stackrel{m}{m}$ & & \\
\hline- & 쪼 & 3 & $\cong$ & $\tilde{\infty}$ & $\dddot{\longleftarrow}$ & 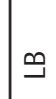 & $\begin{array}{l}\frac{C}{0} \\
\stackrel{\mathbb{U}}{\Sigma}\end{array}$ & $\sum_{3}^{\xi}$ & $\widetilde{o}$ & $\sum_{3}^{2}$ & $\vec{\varangle}$ & $\geqq$ & 兴 & 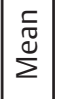 & 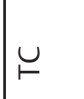 & $\bar{z}$ & $\geqq$ & $\begin{array}{l}\stackrel{\sqrt{0}}{\tilde{d}} \\
\sum\end{array}$ & 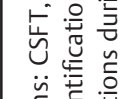 \\
\hline 훈 & $\ll$ & & & & & & & $\infty$ & & & & & & & $\cup$ & & & & \\
\hline
\end{tabular}


controversy exists how often this is possible and at what costs. ${ }^{1}$ When a primary repair appears to be impossible or, at least, will be too long and arduous a solution, some authors advocate an esophageal replacement by stomach, colon, or jejunum. ${ }^{1}$ Several approaches to achieve a primary repair have been used. In some cases of LGEA, spontaneous growth of the segments will allow a delayed anastomosis with the drawbacks being lengthy hospitalization and the risk of aspiration. ${ }^{2}$ More recently, growth induction of the atretic esophageal segments using axial tension provided by traction sutures has been used to achieve a primary repair and has provided early follow-up data. ${ }^{5-7}$ Even a combination of elongation techniques has been reported. ${ }^{8}$ The data on the success rate of lengthening techniques, however, are limited and to gain more insight into this problem, we pooled the experiences of two European centers treating children with LGEA. This experience documents the use of growth techniques, FT and KA, in solving the problem of providing esophageal continuity in LGEA.

Basically, our success rates depended on the gap length, the age of the patients, and more importantly on the management of the SF. The best results were achieved in infants (no newborns were treated) without a SF (group A) ( - Table 1 ). In this group, traction on both pouches resulted in an adequate length to perform the anastomosis within a mean of 3 weeks, and these anastomoses showed the lowest complication rate.

In group B, in which the FT and KA techniques were combined, an adequate length was achieved for all children, but these repairs showed more complications despite being operated on by the same surgeons with the same technique. Two patients had significant infections from leaks during KA, which greatly delayed the anastomosis. These complications raised a concern about whether or not a SF will affect the "quality" of the anastomosis or its healing process. Possibly these esophageal segments contain more fibrous tissue or if the blood vessels were not well preserved during the elongation. On the other hand, the gap length was longer in group B than in group A and the children were older at the time of the first FT (group A: mean of 3 months, group B: mean of 16.4 months). Such comparisons raise the question of whether or not there is an optimal time period for the FT or KA. Spontaneous growth of the esophageal segments may occur during the first 3 months of life and traction-induced growth has been successful to over 2 years of age but unfortunately, there are almost no experimental or scientific data about this phenomenon. $2,5,7$

Problems also occurred with the SFs in group $C$. The length of the gap between groups A and $\mathrm{C}$ did not differ (both 6.5 $\mathrm{cm}$ ), but the age did (3 months vs. 10.6 months). Group C experienced the most serious complications. Leakage from the closure site and severe mediastinitis occurred in two patients during traction and in one from an iatrogenic perforation. In two patients, the esophageal anastomoses could not be performed. The leaks in the SF closes during traction (CSFT) make this approach more risky and not generally advisable.
Another drawback of the FT is the number of thoracotomies and the accompanying surgical trauma. Basically, the FT required only two thoracotomies, one to place the traction sutures and other for the anastomosis. ${ }^{5}$ Any revision of the traction sutures or surgical repair of complications, however, will increase the number of thoracotomies. Our results showed that the mean number of thoracotomies was 2 in group A and 3.6 in group B (range 2 to 8 ), due to complications and traction sutures which pulled out. This is also no doubt that the FT is a more demanding approach technically making the observed complications more likely and the approach riskier initially.

What this study does not address is the long-term results especially in comparison to the most common interposition grafts (stomach and colon as well as the much less commonly used jejunum). Because the goal in pediatric surgery is 70 good years, the answers to the questions surrounding the treatment of LGEA will require at least midterm data 30 to 40 years from treatment. In the meantime, we recognize the potential problems with FT and at one center (Leipzig) have formed an interdisciplinary team which together with the parents discusses each case step by step to set clear goals and define criteria for halting the procedure and going to an interposition graft.

From this experience we conclude: (1) Foker traction of both pouches (group A) produced into a high rate of primary repairs in children with LGEA and no previous esophageal operations. (2) The combination of KA and FT (group B) resulted in an equivalent rate of primary repairs, but the number of thoracotomies and rate of complications increased significantly. (3) CSFT (group C) resulted in a high complication rate. (4) More data are needed, ideally from a multicenter registry, to elucidate the safety and efficacy of each elongation technique and to establish an algorithm with clearer inclusion and exclusion criteria.

\section{Conflict of Interest}

None

\section{References}

1 Tovar JA, Fragoso AC. Current controversies in the surgical treatment of esophageal atresia. Scand J Surg 2011;100(4):273-278

2 Friedmacher F, Puri P. Delayed primary anastomosis for management of long-gap esophageal atresia: a meta-analysis of complications and long-term outcome. Pediatr Surg Int 2012;28(9): 899-906

3 Foker JE, Linden BC, Boyle EM Jr, Marquardt C. Development of a true primary repair for the full spectrum of esophageal atresia. Ann Surg 1997;226(4):533-541, discussion 541-543

4 Foker JE, Linden BC, Boyle EM Jr, Marquardt C. Development of a true primary repair for the full spectrum of esophageal atresia. Ann Surg 1997;226(4):533-541, discussion 541-543

5 Foker JE, Kendall TC, Catton K, Khan KM. A flexible approach to achieve a true primary repair for all infants with esophageal atresia. Semin Pediatr Surg 2005;14(1):8-15

6 Paya K, Schlaff N, Pollak A. Isolated ultra-long gap esophageal atresia-successful use of the Foker technique. Eur J Pediatr Surg 2007;17(4):278-281 
Foker Technique and Kimura Advancement for the Treatment of Children with LGEA Sroka et al. 7

7 Foker JE, Kendall Krosch TC, Catton K, Munro F, Khan KM. Long-gap esophageal atresia treated by growth induction: the biological potential and early follow-up results. Semin Pediatr Surg 2009; 18(1):23-29
8 Till H, Rolle U, Siekmeyer W, Hirsch W, Foker J. Combination of spit fistula advancement and external traction for primary repair of long-gap esophageal atresia. Ann Thorac Surg 2008;86(6): 1969-1971 